Published in final edited form as:

Clin Ther. 2016 January 1; 38(1): 162-179.e6. doi:10.1016/j.clinthera.2015.10.010.

\title{
Efficacy of pramipexole for the treatment of primary restless leg syndrome: a systematic review and meta-analysis of randomized clinical trials
}

\author{
Guang Jian Liu ${ }^{\mathrm{a}, \# \text {, Lang Wu }}{ }^{\mathrm{b}, \#}$, Song Lin Wang ${ }^{\mathrm{a}}$, Li Li Xu ${ }^{\mathrm{a}}$, Li Ying Chang ${ }^{\mathrm{c}}$, and Yun Fu \\ Wang $^{\mathrm{a}}$ \\ aDepartment of Neurology, Taihe Hospital Affiliated to Hubei University of Medicine, Shiyan City, \\ Hubei Province 442000, China \\ ${ }^{b}$ Center for Clinical and Translational Science, Mayo Clinic, Rochester MN 55905, USA \\ 'Department of Neurology, Xiangyang Center Hospital Affiliated to Hubei University of Arts and \\ Science, Xiangyang City, Hubei Province, 441021, China
}

\begin{abstract}
Purpose-The objective of this meta-analysis was to systematically evaluate the efficacy of pramipexole for the treatment of primary moderate to severe RLS.

Methods-Databases of PubMed, OVID, ScienceDirect, SpringerLink, Thomson Reuters Web of Science, the Cochrane Library, the Wiley Online Library, ArticleFirst, CALIS, Study, CNKI, and WanFang were searched to identify randomized controlled trials (RCTs) investigating pramipexole for the treatment of primary moderate to severe RLS. A meta-analysis was then conducted to pool results.
\end{abstract}

\begin{abstract}
Findings-Twelve RCTs involving 3286 participants were included in this study. The average treatment duration was $11.12( \pm 5.72)$ weeks/person. The meta-analysis demonstrated that the posttreatment change in the International Restless Leg Syndrome Study Group Rating Scale (IRLS) score of pramipexole group was significantly superior to that of placebo group (weighted mean difference $(\mathrm{WMD})=-4.64,95 \%$ confidence intervals $(\mathrm{CI})-5.95$ to $-3.33, \mathrm{n}=8)$. More patients in pramipexole group showed at least a 50\% reduction in the IRLS score after treatment (risk ratio $[R R])=1.57,95 \%$ CI 1.43 to $1.73, n=8$ ). In terms of the scores for the Clinical Global Impression of Improvement scale (CGI-I; RR=1.48, 95\% CI 1.31 to $1.66, \mathrm{n}=11$ ) and the Patient Global Impression scale (PGI; RR=1.54, 95\% CI 1.31 to $1.81, \mathrm{n}=9$ ), pramipexole group's treatment
\end{abstract}

\footnotetext{
Corresponding Authors: Yun Fu Wang, Department of Neurology, Taihe Hospital Affiliated to Hubei University of Medicine, Shiyan City, Hubei Province 442000, China. wyfymc@ sina.com. Telephone: +8613971920566. Fax: +8607198883809 or Li Ying Chang, Department of Neurology, Xiangyang Center Hospital Affiliated to Hubei University of Arts and Science, Xiangyang City, Hubei Province, 441021, China. liying_changxf@163.com, Telephone: +8613986388887, Fax: +8607103512850.

\#These authors contributed equally to this article

CONFLICT OF INTEREST

The authors report no disclosures relevant to the manuscript AUTHOR CONTRIBUTIONS

GJL, LW, YFW, LYC designed the study. GJL and LW conducted the literature search and extracted data. SLW and LLX conducted the quality assessment. GJL and LW conducted the statistical analyses. All authors participated in the data interpretation. GJL and LW drafted the first version of the report. All authors revised and approved the final draft of the report.
} 
outcomes were significantly superior to those of placebo group. In terms of the change in quality of life (WMD=5.39, 95\% CI 2.28 to 8.50, $\mathrm{n}=4$ ), change in daytime tiredness (WMD=-0.61, 95\% $\mathrm{CI}-1.21$ to $-0.01, \mathrm{n}=4$ ), change in the number of periodic limb movements per hour of sleep (WMD $=-35.95,95 \% \mathrm{CI}-56.42$ to $-15.48, \mathrm{n}=3$ ) and change in the quality of sleep (WMD=3.60, 95\% CI 1.69 to $5.50, n=6$ ), the treatment outcomes of pramipexole group were significantly superior to those of placebo group.

Implications-This meta-analysis study indicated that pramipexole could effectively improve the symptoms of primary moderate to severe RLS patients, although the quality of evidence was relatively low. Future clinical trials focusing on the medium-term and long-term treatment outcomes and using mainly objective indicators for evaluation are warranted. It is also necessary to pay close attention to augmentation during medication.

\section{Keywords}

Restless leg syndrome (RLS); pramipexole; efficacy; meta-analysis; clinical trials

\section{INTRODUCTION}

Primary restless legs syndrome (RLS) is a common sensorimotor disorder characterized by an irresistible urge to move one's extremities to stop uncomfortable or odd sensations. It commonly affects the lower extremities. The symptom is more severe at rest or at night and can be temporarily relieved by moving the affected extremities. This disorder often interrupts patients' sleep, thus affecting their quality of life. ${ }^{1-3}$ The prevalence rate of RLS in the normal adult population is approximately $3.9 \%-15 \%,{ }^{4,5}$ and the prevalence increases with age. ${ }^{6}$ Approximately one-third of patients require treatment with medication, ${ }^{6}$ which leads to a heavy burden in their daily and social life. ${ }^{3}$ At present, the exact pathophysiology of primary RLS remains unclear. ${ }^{7}$ The results of animal models of RLS and biochemical, postmortem, and imaging studies in patients with the disease suggest that disruptions in brain iron trafficking lead to disturbances in striatal dopamine neurotransmission for at least some patients with RLS ${ }^{7}$. Previous studies have shown that L-dopa can relieve the symptoms by $50 \%$ in approximately $90 \%$ of patients. ${ }^{8}$

In recent years, dopamine agonists have become the first-line drug for RLS treatment. ${ }^{9-11}$ However, this treatment does not achieve satisfactory efficacy in some patients. ${ }^{12,13}$ In addition, it is difficult to maintain the long-term effectiveness of this treatment, and sometimes it even leads to augmentation and/or rebound. ${ }^{10,14}$ Although several previous systematic reviews and meta-analyses have demonstrated that dopamine agonists, e.g., pramipexole and ropinirole, could relieve RLS symptoms and improve sleep ${ }^{15}$ and quality of life, ${ }^{6,16-19}$ selecting a suitable dopamine agonist for a given patient is challenging because one individual can only use one type of dopamine agonist at a time, e.g., pramipexole. At present, a full evaluation of the treatment efficacy of pramipexole is lacking because of the small sample size, limited number of events, and insufficient statistics for certain endpoints in the available trials of pramipexole. ${ }^{20-31}$ In addition, the results from different clinical trials are not completely consistent. ${ }^{20-31}$ To date, only one systematic review has specifically evaluated the efficacy of pramipexole; ${ }^{32}$ however, this review included only six trials ${ }^{22-26,29}$ and evaluated only two endpoints, and the quality of evidence was not classified according 
to the Grading of Recommendations Assessment, Development and Evaluation (GRADE).

Moreover, two relevant clinical trials were published at the beginning of 2014. ${ }^{30,31}$

Therefore, a re-evaluation of the efficacy of pramipexole is of great significance.

\section{METHODS}

This systematic review and meta-analysis were performed according to the Preferred Reporting Items for Systematic Reviews and Meta-analyses statement (PRISMA). ${ }^{33}$ There are no ethical issues involved in our study because our data were based on published studies.

\section{Search Strategies}

We searched databases of PubMed, OVID, ScienceDirect, SpringerLink, Thomson Reuters Web of Science, the Cochrane Library, the Wiley Online Library, ArticleFirst, CALIS, Study, CNKI, and WanFang. The search term for PubMed was "Search (random*) AND ((((restless leg* syndrome) OR Ekbom* syndrome)) AND (pramipexole OR mirapex OR sifrol OR mirapexin))". Each database was searched from its inception date to June 17, 2014. No language restrictions were applied. In addition, we manually screened the reference lists of included trials and newly published reviews. We also screened the Clinical Trial Results web page on Boehringer Ingelheim's website. ${ }^{34}$

\section{Trial Selection}

The inclusion criteria were as follows: (1) Participants: all included patients were older than 18 years and were diagnosed with RLS according to the International Restless Legs Syndrome Study Group diagnostic criteria ${ }^{35}$ or to the clinical version of the Hopkins telephone diagnostic interview, ${ }^{36}$ with a score of at least 15 on the International Restless Leg Syndrome Study Group Rating Scale (IRLS). ${ }^{37}$ The participants discontinued their RLS medications at least 2 weeks before starting the study medications. Pregnant women, substance abusers, and individuals with serious liver or kidney disease, severe insomnia, malignant tumors, Parkinson's disease, or peripheral neuropathy were excluded. (2) Intervention: the trials used pramipexole in pramipexole group and placebo in placebo group, and all drugs were orally administered for at least seven days. No other drugs for RLS were jointly used. (3) Endpoints: the evaluated endpoints included IRLS score, Clinical Global Impression of Improvement scale (CGI-I), ${ }^{38}$ Patient Global Impression scale (PGI), ${ }^{38}$ quality of life and sleep quality. (4) Study type: randomized double-blinded controlled trials were included. We excluded duplicates literatures.

\section{Endpoint Definitions}

The IRLS was established by the International RLS Study Group. This scale contains 10 items and is used to rate the severity of RLS symptoms in the past week. Each item is scored on a range from 0 to 4 , with higher numbers indicating greater severity. The highest possible score is 40 . The higher scores indicate more severe symptoms. ${ }^{37}$ In the present study, we used post-treatment changes in the IRLS score to evaluate symptom changes, and we used the responder rates for the IRLS score to determine the proportion of patients whose IRLS scores were reduced by at least $50 \%$ after treatment. Based on a post-treatment global impression classification of RLS patients (very much improved/better, much improved/ 
better, slightly improved, no change, slightly deteriorated, deteriorated and considerably deteriorated) proposed by the National Institute of Mental Health (NIMH), ${ }^{38}$ we used the responder rates for the CGI-I to investigate the proportion of patients whose symptoms were "very much improved" or "much improved" and used the responder rates for the PGI to investigate the proportion of patients whose symptoms were "very much better" or "much better".

Augmentation was defined as symptomatic worsening of RLS, manifested with earlier onset of symptoms at afternoon or evening, rapid onset or shorter latent of symptoms at rest, severe symptoms, progression of RLS symptoms to other body parts (such as the upper extremities and body trunk, even face), and/or shortened effective duration of medication. ${ }^{39,40}$

\section{Data Extraction}

Using a unified form, two investigators independently extracted the data and created the data spreadsheet. Data accuracy was confirmed by these two investigators together, and discrepancies were resolved via discussion among all researchers participating in this study until a consensus was reached.

The extracted data mainly included the responder rates for the IRLS score, the responder rates for the CGI-I, the responder rates for the PGI, the change in the IRLS score, the change in quality of life, the quality of sleep, the change in the quality of sleep, the change in daytime tiredness, the change in periodic limb movements per hour of sleep, and the number of occurrences/rate of augmentation. To determine the post-treatment change from the baseline means, all of the increased data were presented as positive numbers, and all of the decreased data were presented as negative numbers on the data spreadsheet. All of the data were extracted based on an intention-to-treat analysis (ITT), and a portion of the data were also extracted based on the last observation carried forward (LOCF). In this study, we also included some of the data from the study by Scholz et al. ${ }^{6}$, in addition to the data extracted from original literature and the results reported on the Clinical Trial Results web page of Boehringer Ingelheim's website. ${ }^{34}$

\section{Publication Bias Evaluation and Data Quality Grading}

Two investigators evaluated the publication bias of all included trials according to the Cochrane Collaboration's tool for assessing bias (Reviewer's Handbook ${ }^{41}$ ) and graded the evidence quality of all endpoints based on the GRADE profile version 3.6 provided by the GRADE study group. The risk of bias for certain studies was adopted from the study by Scholz et al. ${ }^{6}$

\section{Statistical Analysis}

The risk ratio (RR) was used to investigate the responder rates for the IRLS score, the responder rates for the CGI-I, the responder rates for the PGI, and augmentation. An RR higher than 1 indicated that pramipexole group's response was superior to that of placebo group. The weighted mean difference (WMD) was used to evaluate continuous variables, including end-of-treatment data and changes from baseline means, which were expressed 
using the same measurement units. For the change in the IRLS scores, the change in daytime tiredness, and the change in periodic limb movements per hour of sleep, a negative WMD indicated that pramipexole group's response was superior to that of placebo group. For the quality of sleep, the change in quality of life, and the change in the quality of sleep, a positive WMD indicated that pramipexole group's response was superior to that of placebo group.

Prior to the meta-analysis of each item, Chi-square tests were performed to test inter-trial heterogeneity; $\mathrm{p} \geq 0.10$ and $\mathrm{I}^{2} \leq 40 \%$ indicated the absence of significant heterogeneity, and a fixed-effects model was applied; otherwise, a random-effects model was applied for analysis. For pooling data, the Mantel-Haenszel method was applied for binary variables, and the Inverse-Variance method was applied for continuous variables. The sensitivity and publication bias of each endpoint with statistical significance were evaluated. Sensitivity was analyzed by removing each trial one at a time, and publication bias was detected using an Egger test ${ }^{42}$. Chi square tests were applied to compare the rate of loss to follow-up and the proportion of female patients in pramipexole group versus placebo group from the same trial. SPSS Predictive Analytics Software version 18.0 (SPSS, Inc., Chicago, IL, USA) was used for the chi square tests, and Stata Statistical Software version SE 12.0 (Stata Corp LP, College Station, TX, USA) was used for all other analyses.

\section{RESULTS}

\section{Search Results and Trial Characteristics}

A total of 576 records were identified through database search, after we excluded two studies that used a self-control method before and after treatment, ${ }^{43,44}$ two trials that did not include a washout period prior to the treatment, ${ }^{45,46}$ one trial that used healthy volunteers as controls ${ }^{47}$ one trial that had a treatment duration less than seven days, ${ }^{48}$ and nine repeated records,${ }^{49-57}$ twelve trials were ultimately included in our study. ${ }^{20-31}$

All of the included trials were double-blinded randomized placebo-controlled trials, which included a total of 3286 participants who underwent an intention-to-treat analysis. Among the included trials, ten ${ }^{20,22-30}$ were parallel controlled, and two ${ }^{21,31}$ were cross-controlled. Eleven of the trials ${ }^{21-31}$ were published in peer-reviewed journals; the remaining trial ${ }^{20}$ was published at the Clinical Trial Results web page on Boehringer Ingelheim's website. ${ }^{34}$ Eleven of the trials employed the international RLS diagnostic criteria, ${ }^{20-29,31}$ and the other adopted the clinical version of the Hopkins telephone diagnostic interview. ${ }^{30}$

The available data demonstrated that ten of the trials involved patients who had moderate to severe symptoms or an IRLS score $\geq 15 .{ }^{22-31}$ The trial by Montplaisir et al. ${ }^{21}$ reported that the RLS symptoms interrupted sleep more than three times per week. Participants were treated for three weeks in one trial, ${ }^{22}$ six to eight weeks in five trials, ${ }^{20,21,24,26,29}$ twelve weeks in five trials, ${ }^{23,25,28,30,31}$ and twenty-six weeks in one trial, ${ }^{27}$ yielding an average treatment duration of $11.12( \pm 5.72)$ (mean $\pm \mathrm{SD})$ weeks/person (median: 12 weeks/person). In all of the included trials, drugs were administered $2-3 \mathrm{~h}$ before sleep every day, with the minimal dose of $0.125 \mathrm{mg} /$ day and the maximal dose of $1.5 \mathrm{mg} /$ day. All of the trials were 
supported by pharmaceutical companies, including nine 20,22-29 $^{2}$ supported by Boehringer Ingelheim Co., two ${ }^{30,31}$ by Pfizer, and one ${ }^{21}$ by Pharmacia and Upjohn.

The rates of loss to follow-up (i.e. the proportion of participants who took the experimental drug at least once but never completed an effective endpoint assessment) in the included trials ranged from $0 \%$ to $9.76 \%$, with an average rate of $2.62 \%$ (86/3286). With the exceptions of the trials by Inoue et al. ${ }^{26}(9.76 \% ; 0 \%$ in pramipexole group and $19.05 \%$ in placebo group, $\mathrm{p}=0.040)$ and $\mathrm{Ma}$ et al. ${ }^{29}(6.23 \% ; 3.96 \%$ in pramipexole group and $10.68 \%$ in placebo group, $\mathrm{p}=0.022$ ), there was no statistically significant difference in the rate of loss to follow-up between the two groups ( $p>0.05$ ). The LOCF method was employed for incomplete outcome data in three trials, ${ }^{23,26,28}$ and polysomnogram (PSG) was used in four trials. $^{21,22,26,31}$

All of the included trials were multicenter trials; five were completed in Europe and North American, ${ }^{21,23,27,30,31}$ four in Europe, ${ }^{22,24,25,28}$ one in China, ${ }^{29}$ and one in Japan. ${ }^{26}$ Except for the trials by Ma et al. ${ }^{29}(\mathrm{p}=0.048)$ and Oertel et al. ${ }^{24}(\mathrm{p}=0.001)$, in which the females accounted for a significantly greater proportion in placebo group than that in pramipexole group, and the trial by Montagna et al., ${ }^{28}$ in which the proportion of female participants in placebo group was slightly higher than that in pramipexole group $(\mathrm{p}=0.053)$, the baseline characteristics of all other included trials were comparable between the two groups ( $p>0.05) .{ }^{20-31}$ The screening process is presented in Figure 1, and the main characteristics of the 12 included trials are presented in Table 1.

\section{Risk of Bias}

We adopted the risk of bias evaluation results for nine trials ${ }^{20-28}$ reported by Scholz et al. ${ }^{6}$ Except for BI248.616 ${ }^{20}$ and the trial by Inoue et al., ${ }^{26}$ in which the risk of "random sequences generation (selection bias)" was unclear, all other included trials had low risks of bias (Supplementary Materials: Figure S1 and Figure S2).

\section{GRADE}

The GRADE rating revealed that no endpoints had high-quality evidence, two endpoints had medium-quality evidence, six had low-quality evidence, and one had extremely low-quality evidence (Table 2).

\section{Change in the IRLS}

The meta-analysis of eight trials ${ }^{20,22-25,27-29}$ demonstrated that the post-treatment change in the IRLS score of pramipexole group was significantly superior to that of placebo group (WMD $=-4.64,95 \% \mathrm{CI}-5.95$ to -3.33 ). The intragroup heterogeneity test yielded results of $\mathrm{I}^{2}=70.4 \%$ and $\mathrm{p}=0.001$ (Figure 2).

\section{Responder rates for the IRLS score}

The meta-analysis of eight trials ${ }^{22-29}$ revealed that compared with placebo group, pramipexole group had a significantly higher proportion of patients whose IRLS score 
decreased by at least $50 \%$ after treatment $(\mathrm{RR}=1.57,95 \% \mathrm{CI} 1.43$ to 1.73$)$. The intragroup heterogeneity test yielded results of $\mathrm{I}^{2}=0$ and $\mathrm{p}=0.514$ (Figure 3 ).

\section{Responder rates for the CGI-I}

The meta-analysis of 11 trials ${ }^{20,22-31}$ showed that compared with placebo group, pramipexole group had a significantly higher proportion of patients whose symptoms were "very much improved" or "much improved" after treatment according to doctors (RR=1.48, 95\% CI 1.31 to 1.66). The intragroup heterogeneity test yielded results of $\mathrm{I}^{2}=62.0 \%$ and $\mathrm{p}=0.003$ (Figure 3); after the removal of $\mathrm{BI} 248.616,{ }^{20}$ the intragroup heterogeneity test yielded results of $\mathrm{I}^{2}=36.2 \%$ and $\mathrm{p}=0.118$.

\section{Responder rates for the PGI}

The meta-analysis of nine trials ${ }^{20,22-29}$ showed that compared with placebo group, pramipexole group had a significantly higher proportion of patients whose symptoms were "very much better" or "much better" after treatment, as perceived by patients themselves ( $\mathrm{RR}=1.54,95 \% \mathrm{CI} 1.31$ to 1.81$)$. The intragroup heterogeneity test yielded results of $\mathrm{I}^{2}=71.1 \%$ and $\mathrm{p}=0.001$ (Figure 3); after the removal of BI248.616, ${ }^{20}$ the intragroup heterogeneity test yielded results of $\mathrm{I}^{2}=26.5 \%$ and $\mathrm{p}=0.217$.

\section{Quality of life}

The results reported in the trials by Ferini-Strambi et al..$^{25}$ and Montagna et al. ${ }^{28}$ demonstrated that compared with placebo group, pramipexole group showed significantly decreased in the RLS-QOL score after treatment $(\mathrm{p}=0.01 ; \mathrm{p}<0.001)$. However, in one trial, ${ }^{27}$ the improvement in the RLS-QOL score did not differ significantly between the two groups after treatment $(\mathrm{p}=0.591)$. The results reported in the trial by Partinen et al. ${ }^{22}$ demonstrated that other than the social function score (a subscale), which was higher in pramipexole group than in placebo group, all of the other scores related to life quality (SF-36) did not show a statistically significant difference between the two groups after treatment $(p>0.05)$. Only the trial by Allen et al. ${ }^{30}$ reported scores for the quality of life; thus, the data were insufficient for pooling. The meta-analysis of four trials ${ }^{23,25,27,28}$ revealed that in terms of the change in quality of life, the treatment outcome of pramipexole group was superior to that of placebo group (WMD=5.39, 95\% CI 2.28 to 8.50 ). The intragroup heterogeneity test yielded results of $\mathrm{I}^{2}=67.7 \%$ and $\mathrm{p}=0.026$ (Figure 4 ); after the trial by Hogl et al. ${ }^{27}$ was removed, the results were $\mathrm{I}^{2}=14.0 \%$ and $\mathrm{p}=0.313$.

\section{Quality of sleep}

The meta-analysis of two trials ${ }^{30,31}$ indicated that the current evidence was insufficient to prove that the improvement of sleep quality was greater in pramipexole group compared with placebo group (WMD $=0.51,95 \%$ CI -0.03 to 1.06 ; Figure 4). The trial by Montplaisir et al. ${ }^{21}$ revealed that compared with placebo group, pramipexole group experienced a $98 \%$ decrease in periodic limb movement in sleep index, and the number of periodic limb movements, the number of sleep interruptions related to periodic limb movement, and the number of periodic waking at night all significantly decreased (all $\mathrm{p}<0.01$ ). 
The meta-analysis of four trials ${ }^{24,25,27,28}$ showed that regarding the change in daytime tiredness, pramipexole group had a superior treatment outcome compared with placebo group (WMD $=-0.61,95 \% \mathrm{CI}-1.21$ to -0.01 ); the intragroup heterogeneity test yielded results of $\mathrm{I}^{2}=73.3 \%$ and $\mathrm{p}=0.010$ (Figure 2). The result obtained by Garcia-Borreguero et al. ${ }^{31}$ indicated that compared with placebo group, pramipexole group showed significantly improved results of periodic limb movement in sleep index (pramipexole group vs. placebo group (mean \pm standard error): $8.0( \pm 2.4)$ vs. $37.0( \pm 2.5)$, $\mathrm{p}<0.05)$. The meta-analysis of three trials ${ }^{21,22,26}$ showed that regarding the change in periodic limb movements per hour of sleep, pramipexole group had a superior treatment outcome compared with placebo group (WMD $=-35.95,95 \% \mathrm{CI}-56.42$ to -15.48 ); the intragroup heterogeneity test yielded results of $\mathrm{I}^{2}=91.3 \%$ and $\mathrm{p}<0.001$ (Figure 2). The meta-analysis of six trials ${ }^{22-26,28}$ showed that in terms of the change in quality of sleep, pramipexole group had a superior treatment outcome compared with placebo group (WMD $=3.60,95 \%$ CI 1.69 to 5.50); the intragroup heterogeneity test yielded results of $\mathrm{I}^{2}=87.7 \%$ and $\mathrm{p}<0.001$ (Figure 4 ).

\section{Augmentation}

Among the included trials, two 27,30 assessed the occurrence of augmentation, and one ${ }^{30}$ evaluated the rate of augmentation in the pramipexole and pregabaline group without mentioning the placebo group. The analysis result of one trial ${ }^{27}$ demonstrated that the risk of augmentation in patients treated with pramipexole was comparable to that of the placebo group (pramipexole vs. placebo: $\mathrm{RR}=1.40,95 \% \mathrm{CI}, 0.62$ to 3.13 ).

\section{Sensitivity analysis}

The sensitivity analysis indicated that for the change in daytime tiredness, after the removal of any one trial other than the one by Hogl et al., ${ }^{27}$ the upper limit of the 95\% CI of WMD was higher than zero, indicating that the results for this endpoint were affected by the other three trials. For the change in periodic limb movements per hour of sleep, the upper limit of the $95 \%$ CI of WMD was higher than zero after the removal of any one trial, indicating that the results for this endpoint were affected by the other trials (Supplementary Materials:Figure S3 and S4).

For the change in the IRLS score, the upper limit of the 95\% CI of WMD was lower than zero after the removal of any one trial. For the change in quality of life and the change in quality of sleep, the lower limit of the 95\% CI of WMD remained higher than zero after the removal of any one trial. For the responder rates for the IRLS scores, the responder rates for the CGI-I, and the responder rates for the PGI, the lower limit of the 95\% CI of RR remained higher than 1 after the removal of any one trial. These results indicated that the results for these endpoints were robust (Supplementary Materials: Figure S5-S10).

\section{Publication Bias}

The Egger test derived a p value less than 0.05 for the change in quality of sleep, indicating the existence of a publication bias for this endpoint. For the other endpoints, the $\mathrm{p}$ values were all greater than 0.05 , indicating the absence of evident publication bias for these endpoints (Table 3). 


\section{DISCUSSION}

This study demonstrated that for patients with primary moderate to severe RLS, pramipexole showed a higher treatment efficacy compared with placebo for eight endpoints, including the change in the IRLS scores, the proportion of patients whose IRLS score decreased by at least $50 \%$ after treatment, CGI-I, PGI, the change in quality of life, the change in daytime tiredness, the change in periodic limb movements during sleep and the change in quality of sleep.

This study has the several strengths. Firstly, the literature search was comprehensive and reproducible. We searched twelve major databases and screened the Clinical Trial Results web page on Boehringer Ingelheim's website. ${ }^{34}$ This study included all RCTs that were completed.

Secondly, all of the included trials had a relatively low risk of bias. All trials were multicenter, placebo-controlled, randomized and double-blinded international trials. Each participant was assigned a serial number that was randomly generated by computers at the pharmaceutical company and was randomly allocated based on the participant's location and the proportion of study subjects recruited from that site. The researchers did not know the details of the randomized allocation and were not able to change the randomizing process. The data in each trial were managed by specific personnel to ensure the blinding of the participants, doctors and outcome evaluators. Therefore, these trials had low risks of bias.

Thirdly, the trial results were reliable. Except for the two trials ${ }^{26,29}$ in which the rate of loss to follow-up of placebo group was higher than that of pramipexole group, and the two trials $^{24,29}$ in which the proportion of females in placebo group was higher than the proportion in pramipexole group, the baseline data of all other trials were completely comparable between the two groups. Moreover, the highest rate of loss to follow-up $\left(9.76 \%^{26}\right)$ among all of the included trials was far below $20 \%$, and the average rate was only $2.62 \%$. Therefore, the results reported in those trials were trustworthy.

Fourthly, our conclusions were representative and generalizable. The involved participants were outpatients who had moderate to severe symptoms, and the participants included Caucasians, Asians, and black people from Europe, North America and Asia. Therefore, the data from these participants could effectively reflect the treatment needs of patient populations from the abovementioned races and areas, and consequently, our conclusions from the present study are extensively applicable.

It is worth noting that except for the responder rates for the IRLS score and quality of sleep, there were different levels of heterogeneity for the endpoints ( $\mathrm{I}^{2} 62.0 \%$ to $91.3 \%$; Figure 24). The trial by Hogl et al. ${ }^{27}$ was the major contributor to the heterogeneity of the change in quality of life, possibly because it used a significantly longer treatment duration compared with other trials. In other words, compared with a 12-week treatment, using pramipexole for 26 consecutive weeks was not more effective for improving quality of life. The BI248.616 trial $^{20}$ was the major contributor to the heterogeneity of the responder rates for the PGI and the responder rates for the CGI-I, which could be attributed to its treatment regimen in which half of the patients in pramipexole group were treated with a fixed drug dose. In other 
words, the administration of pramipexole at a fixed dose of $0.25 \mathrm{mg} /$ day reduced the possibility that a portion of patients would achieve satisfactory outcomes; administering the drug at a dose adjusted according to the individual's response could provide more satisfactory symptom improvement.

Regarding the publication bias related to the change in sleep quality ${ }^{22-26,28}$, possible explanations were as follows: Firstly, the patients who have poor treatment outcomes are more likely to be lost to follow-up. A significantly higher rate of loss to follow-up in placebo group compared with pramipexole group in the trial by Inoue et al. ${ }^{26}$ might contribute to the occurrence of bias. Secondly, all of the trials received financial support from pharmaceutical companies. Finally, similar to the statement of Scholz et al., ${ }^{6}$ we cannot completely rule out the potential influence of other factors, such as older age, more severe symptoms, and a stronger response to the treatment.

Unlike the study conducted by Zhang et al., ${ }^{32}$ the present study included a greater number of existing trials, rated the quality of evidence for all endpoints according to GRADE, performed a sensitivity analysis, conducted publication bias identification and source analysis of heterogeneity. In addition, this study confirmed the efficacy of pramipexole from various perspectives, such as the proportion of patients with an IRLS score reduction of at least $50 \%$ after treatment, CGI-I, PGI, and the change in quality of life. Compared with previous studies ${ }^{6,16-19}$, this study specifically evaluated the efficacy of pramipexole, included a larger number of clinical trials, involved a larger sample size, and conducted indepth analyses of each endpoint regarding sensitivity, publication bias, and heterogeneity sources. This study revealed that pramipexole could reduce the IRLS score by 4.64 points (pramipexole vs. placebo: $\mathrm{WMD}=-4.64,95 \% \mathrm{CI}-5.95$ to -3.33 ), showing a smaller point estimated value and a slightly expanded $95 \%$ CI compared with previous studies in which the IRLS score was reduced by 5.74 points (dopamine agonists vs. placebo: WMD=-5.74, $95 \% \mathrm{CI}-6.74$ to -4.74$)^{17}$ and by 5.47 points (dopamine agonists vs. placebo: $\mathrm{WMD}=-5.47$ $95 \%$ CI -6.40 to -4.54$)^{6,19}$ after treatment with dopamine agonists. This result might be attributable to the single type of dopamine receptor agonist used (only pramipexole) and the smaller number of clinical trials included.

Because of the limitations of data availability of the existing trials, this study did not find a higher risk of augmentation among patients treated with pramipexole compared with patients treated with placebo. However, other studies did indicate that pramipexole could result in a high augmentation rate of 7.83\%-47.06\% ${ }^{30,58-62}$ and could even lead to termination of treatment in some patients. ${ }^{59}$ Therefore, during medication, particularly during long-term treatment, it is necessary to pay close attention to the occurrence of augmentation. Recent guidelines have also included similar warnings. ${ }^{63}$

Our study has several limitations which should be acknowledged. Firstly, except for one endpoint (the change in periodic limb movements per hour of sleep) measured under PSG monitoring, other endpoints were mainly subjective evolution indicators. Secondly, because each trial had its specific focus, not all endpoints were reported in all trials, leading to an insufficient statistical assessment for these different endpoints. For example, pramipexole did not show the anticipated advantage in terms of quality of sleep $(n=2)$, but it showed 
significant superiority to placebo in terms of the change in quality of sleep ( $n=6$; Figure 4).

In addition, the insufficiency of the relevant trials and relatively small sample size also led to an increased sensitivity of the change in daytime tiredness and change in periodic limb movements per hour of sleep. Thirdly, because of the existence of heterogeneity and the financial sponsorship of pharmaceutical companies, the quality of evidence based on GRADE was relatively low. Fourthly, the medium-term and long-term efficacy was not evaluated because of the short average treatment duration of only $11.12( \pm 5.72)$ weeks/ person.

It is worth emphasizing that because the pathogenesis and mechanisms of RLS remain unclear and because the drugs targeting the dopamine system dysfunction can only reduce the symptoms by $50 \%$ in approximately $90 \%$ patients, ${ }^{8}$ it is not practical to anticipate that the use of dopamine agonists could eliminate all symptoms of RLS. For patients who have severe symptoms and do not respond to first-line drugs, it may be warranted to jointly take multiple drugs. ${ }^{10,64}$

\section{CONCLUSIONS}

This meta-analysis demonstrated that pramipexole use could effectively improve the symptoms of primary moderate to severe RLS patients, Due to the fact that the quality of evidence was relatively low, future clinical trials focusing on the medium-term and longterm outcomes and using mainly objective indicators for evaluation are warranted to replicate our findings.

\section{Supplementary Material}

Refer to Web version on PubMed Central for supplementary material.

\section{Acknowledgments}

We sincerely thank Mr. Ya Jun Li (the Library of Hubei University of Medicine) for his help with the literature searches. We also greatly appreciate the help of Dr. Hui Nie (diyahui912@gmail.com) from Durham of North Carolina, U.S.A. with the translation of this manuscript.

\section{References}

1. Innes KE, Selfe TK, Agarwal P. Restless legs syndrome and conditions associated with metabolic dysregulation, sympathoadrenal dysfunction, and cardiovascular disease risk: a systematic review. Sleep Med Rev. 2012; 16:309-339. [PubMed: 21733722]

2. Bogan RK, Cheray JA. Restless legs syndrome: a review of diagnosis and management in primary care. Postgrad Med. 2013; 125:99-111. [PubMed: 23748511]

3. Comella CL. Treatment of restless legs syndrome. Neurotherapeutics. 2014; 11:177-187. [PubMed: 24363103]

4. Ohayon MM, O'Hara R, Vitiello MV. Epidemiology of restless legs syndrome: a synthesis of the literature. Sleep Med Rev. 2012; 16:283-295. [PubMed: 21795081]

5. Yeh P, Walters AS, Tsuang JW. Restless legs syndrome: a comprehensive overview on its epidemiology, risk factors, and treatment. Sleep Breath. 2012; 16:987-1007. [PubMed: 22038683]

6. Scholz H, Trenkwalder C, Kohnen R, Riemann D, Kriston L, Hornyak M. Dopamine agonists for restless legs syndrome. Cochrane Database Syst Rev. 2011:CD006009. [PubMed: 21412893] 
7. Earley CJ, Connor J, Garcia-Borreguero D, et al. Altered Brain iron homeostasis and dopaminergic function in Restless Legs Syndrome (Willis-Ekbom Disease). Sleep Med. 2014

8. Stiasny-Kolster K, Kohnen R, Moller JC, Trenkwalder C, Oertel WH. Validation of the "L-DOPA test" for diagnosis of restless legs syndrome. Mov Disord. 2006; 21:1333-1339. [PubMed: 16705685]

9. Aurora RN, Kristo DA, Bista SR, et al. The treatment of restless legs syndrome and periodic limb movement disorder in adults--an update for 2012: practice parameters with an evidence-based systematic review and meta-analyses: an American Academy of Sleep Medicine Clinical Practice Guideline. Sleep. 2012; 35:1039-1062. [PubMed: 22851801]

10. Buchfuhrer MJ. Strategies for the treatment of restless legs syndrome. Neurotherapeutics. 2012; 9:776-790. [PubMed: 22923001]

11. Sethi KD, Mehta SH. A clinical primer on restless legs syndrome: what we know, and what we don't know. Am J Manag Care. 2012; 18:S83-S88. [PubMed: 23009275]

12. Earley CJ, Silber MH. Restless legs syndrome: understanding its consequences and the need for better treatment. Sleep Med. 2010; 11:807-815. [PubMed: 20817595]

13. Godau J, Spinnler N, Wevers AK, Trenkwalder C, Berg D. Poor effect of guideline based treatment of restless legs syndrome in clinical practice. J Neurol Neurosurg Psychiatry. 2010; 81:1390-1395. [PubMed: 20884674]

14. Garcia-Borreguero D, Williams AM. Dopaminergic augmentation of restless legs syndrome. Sleep Med Rev. 2010; 14:339-346. [PubMed: 20219397]

15. Hansen RA, Song L, Moore CG, et al. Effect of ropinirole on sleep outcomes in patients with restless legs syndrome: meta-analysis of pooled individual patient data from randomized controlled trials. Pharmacotherapy. 2009; 29:255-262. [PubMed: 19249945]

16. Zintzaras E, Kitsios GD, Papathanasiou AA, et al. Randomized trials of dopamine agonists in restless legs syndrome: a systematic review, quality assessment, and meta-analysis. Clin Ther. 2010; 32:221-237. [PubMed: 20206780]

17. Hornyak M, Trenkwalder C, Kohnen R, Scholz H. Efficacy and safety of dopamine agonists in restless legs syndrome. Sleep Med. 2012; 13:228-236. [PubMed: 22281001]

18. Wilt TJ, MacDonald R, Ouellette J, et al. Pharmacologic therapy for primary restless legs syndrome: a systematic review and meta-analysis. JAMA Intern Med. 2013; 173:496-505. [PubMed: 23460396]

19. Hornyak M, Scholz H, Kohnen R, Bengel J, Kassubek J, Trenkwalder C. What treatment works best for restless legs syndrome? Meta-analyses of dopaminergic and non-dopaminergic medications. Sleep Med Rev. 2014; 18:153-164. [PubMed: 23746768]

20. Boehringer Ingelheim. [last accessed 21 June 2014] BI 248.616. A Phase IV randomised, doubleblind, active and placebo-controlled, 6-week trial to investigate the efficacy and safety of a starting (and fixed) dose $0.25 \mathrm{mg}$ pramipexole (Mirapex ${ }^{\circledR}$ ) in patients with idiopathic Restless Legs Syndrome. 2008. Available from: http://trials.boehringer-ingelheim.com/content/dam/internet/opu/ clinicaltrial/com_EN/results/248/248.616_U08-3876.pdf

21. Montplaisir J, Nicolas A, Denesle R, Gomez-Mancilla B. Restless legs syndrome improved by pramipexole: a double-blind randomized trial. Neurology. 1999; 52:938-943. [PubMed: 10102409]

22. Partinen M, Hirvonen K, Jama L, et al. Efficacy and safety of pramipexole in idiopathic restless legs syndrome: a polysomnographic dose-finding study--the PRELUDE study. Sleep Med. 2006; 7:407-417. [PubMed: 16815748]

23. Winkelman JW, Sethi KD, Kushida CA, et al. Efficacy and safety of pramipexole in restless legs syndrome. Neurology. 2006; 67:1034-1039. [PubMed: 16931507]

24. Oertel WH, Stiasny-Kolster K, Bergtholdt B, et al. Efficacy of pramipexole in restless legs syndrome: a six-week, multicenter, randomized, double-blind study (effect-RLS study). Mov Disord. 2007; 22:213-219. [PubMed: 17133582]

25. Ferini-Strambi L, Aarskog D, Partinen M, et al. Effect of pramipexole on RLS symptoms and sleep: a randomized, double-blind, placebo-controlled trial. Sleep Med. 2008; 9:874-881. [PubMed: 18952497] 
26. Inoue Y, Hirata K, Kuroda K, et al. Efficacy and safety of pramipexole in Japanese patients with primary restless legs syndrome: A polysomnographic randomized, double-blind, placebocontrolled study. Sleep Med. 2010; 11:11-16. [PubMed: 19962941]

27. Hogl B, Garcia-Borreguero D, Trenkwalder C, et al. Efficacy and augmentation during 6 months of double-blind pramipexole for restless legs syndrome. Sleep Med. 2011; 12:351-360. [PubMed: 21354368]

28. Montagna P, Hornyak M, Ulfberg J, et al. Randomized trial of pramipexole for patients with restless legs syndrome (RLS) and RLS-related impairment of mood. Sleep Med. 2011; 12:34-40. [PubMed: 20965780]

29. Ma JF, Wan Q, Hu XY, et al. Efficacy and safety of pramipexole in chinese patients with restless legs syndrome: results from a multi-center, randomized, double-blind, placebo-controlled trial. Sleep Med. 2012; 13:58-63. [PubMed: 22137119]

30. Allen RP, Chen C, Garcia-Borreguero D, et al. Comparison of pregabalin with pramipexole for restless legs syndrome. N Engl J Med. 2014; 370:621-631. [PubMed: 24521108]

31. Garcia-Borreguero D, Patrick J, DuBrava S, et al. Pregabalin versus pramipexole: effects on sleep disturbance in restless legs syndrome. Sleep. 2014; 37:635-643. [PubMed: 24899755]

32. Zhang W, Wang Y, Cong SY, Nao JF, Feng J, Bi GR. Efficacy and tolerability of pramipexole for the treatment of primary restless leg syndrome: a meta-analysis of randomized placebo-controlled trials. Neuropsychiatr Dis Treat. 2013; 9:1035-1043. [PubMed: 23950645]

33. Liberati A, Altman DG, Tetzlaff J, et al. The PRISMA statement for reporting systematic reviews and meta-analyses of studies that evaluate health care interventions: explanation and elaboration. PLoS Med. 2009; 6:e1000100. [PubMed: 19621070]

34. Boehringer Ingelheim. [Last accessed 21 May 2014] http://trials.boehringer-ingelheim.com/ trial_results/clinical_trials_overview/clinical_trial_result.c=n.i $=. \mathrm{html}$

35. Allen RP, Picchietti D, Hening WA, Trenkwalder C, Walters AS, Montplaisi J. Restless legs syndrome: diagnostic criteria special considerations and epidemiology. A report from the restless legs syndrome diagnosis and epidemiology workshop at the National Institutes of Health. Sleep Med. 2003; 4:101-119. [PubMed: 14592341]

36. Hening WA, Allen RP, Washburn M, Lesage S, Earley CJ. Validation of the Hopkins telephone diagnostic interview for restless legs syndrome. Sleep Med. 2008; 9:283-289. [PubMed: 17644424]

37. Walters AS, LeBrocq C, Dhar A, et al. Validation of the International Restless Legs Syndrome Study Group rating scale for restless legs syndrome. Sleep Med. 2003; 4:121-132. [PubMed: 14592342]

38. National Institute of Mental Health (NIMH). Early clinical drug evaluation unit (ECDEU). Clinical global impressions. In: Guy, W., editor. ECDEU assessment manual for psychopharmacology (rev.). NIMH USA, Rockville, MD: 1976.

39. Garcia-Borreguero D, Allen RP, Kohnen R, et al. Diagnostic standards for dopaminergic augmentation of restless legs syndrome: Report from a World Association of Sleep Medicine International Restless Legs Syndrome Study Group consensus conference at the Max Planck Institute. Sleep Med. 2007; 8:520-530. [PubMed: 17544323]

40. Garcia-Borreguero D, Kohnen R, Hogl B, et al. Validation of the Augmentation Severity Rating Scale (ASRS): a multicentric, prospective study with levodopa on restless legs syndrome. Sleep Med. 2007; 8:455-463. [PubMed: 17543579]

41. Higgins, JPT.; Green, S. [Accessed November 11, 2014] The Cochrane Handbook for Systematic Reviews of Interventions 5.1.0. The Cochrane Collaboration Web site. 2011. http:// handbook.cochrane.org/

42. Egger M, Davey SG, Schneider M, Minder C. Bias in meta-analysis detected by a simple, graphical test. BMJ. 1997; 315:629-634. [PubMed: 9310563]

43. ClinicalTrials.gov (A service of the U.S. National Institutes of Health). [last accessed 21 June 2014] A Randomised, Comparing Fixed Doses of Pramipexole to Investigate the Efficacy and Safety in Patients with RLS. 2013. Available from: http://clinicaltrials.gov/ct2/show/ NCT00390689?term $=$ pramipexole\&rank $=20$ 
44. Inoue Y, Kuroda K, Hirata K, Uchimura N, Kagimura T, Shimizu T. Efficacy, safety and doseresponse of pramipexole in Japanese patients with primary restless legs syndrome: randomized trial. Neuropsychobiology. 2011; 63:35-42. [PubMed: 21063131]

45. ClinicalTrials.gov (A service of the U.S. National Institutes of Health). [last accessed 21 June 2014] Polysomnography Study of Pregabalin and Pramipexole versus Placebo in Patients with Restless Legs Syndrome and Associated Sleep Disturbance. 2012. Available from: http:// clinicaltrials.gov/ct2/show/NCT00991276?term=pramipexole\&rank=35

46. Trenkwalder C, Stiasny-Kolster K, Kupsch A, Oertel WH, Koester J, Reess J. Controlled withdrawal of pramipexole after 6 months of open-label treatment in patients with restless legs syndrome. Mov Disord. 2006; 21:1404-1410. [PubMed: 16755554]

47. Ferri R, Manconi M, Plazzi G, et al. Leg movements during wakefulness in restless legs syndrome: time structure and relationships with periodic leg movements during sleep. Sleep Med. 2012; 13:529-535. [PubMed: 22341907]

48. Manconi M, Ferri R, Zucconi M, et al. Preferential D2 or preferential D3 dopamine agonists in restless legs syndrome. Neurology. 2011; 77:110-117. [PubMed: 21715702]

49. Partinen M, Hirvonen K, Jama L, et al. Effects of pramipexole on periodic limb movements (PLMs) in restless legs syndrome (RLS): A polysomnographic study. Sleep Med. 2006; 7(Suppl): 126-127.

50. Partinen M, Hirvonen K, Jama L, et al. Clinician ratings and patient self-ratings of improvement after 3 weeks of double-blind placebo-controlled pramipexole for restless legs syndrome (RLS). Sleep Med. 2006; 7(Suppl):126.

51. Hirvonen, k; Partinen, M.; Jama, L.; Alakuijala, A.; Hublin, C. Efficacy of pramipexole by clinician and patient assessment during a polysomnographic (PSG) study of restless legs syndrome (RLS). Sleep Med. 2007; 7(Suppl):71.

52. Jama L, Partinen M, Hirvonen K, et al. Pramipexole significantly reduces periodic limb movement index (PLMI) in restless legs syndrome (RLS). Sleep Med. 2007; 8(Suppl):70.

53. Partinen M, Hirvonen K, Jama L, et al. In patients with restless legs syndrome (RLS), pramipexole significantly improves periodic limb movements during time in bed index (PLMI). Sleep Med. 2007; 8(Suppl):72.

54. Stiasny-Kolster K, Oertel WH, Bergtholdt B, et al. Sleep self-assessment by visual analogue scales (VASs) in a 6-week European trial of pramipexole for restless legs syndrome (RLS). Sleep Med. 2007; 8(Suppl):71.

55. Hornyak M, Sohr M, Busse M. Evaluation of painful sensory symptoms in restless legs syndrome: experience from two clinical trials. Sleep Med. 2011; 12:186-189. [PubMed: 21256799]

56. Garcia-Borreguero D, Chen C, Allen RP, et al. Long-Term Efficacy and Augmentation Assessment of a Dopamine Agonist(Pramipexole) Compared with an Alpha-2-Delta Ligand (Pregabalin) in Restless Legs Syndrome: Results of a Randomized, Double-Blinded, Placebo-Controlled Trial. Neurology. 2012; 79:e87-e87e91.

57. Garcia-Borreguero D, Chen C, Allen RP, et al. Effects of pregabalin and pramipexole on sleep and quality of life in patients with restless legs syndrome: results from a long-term, randomised, double-blinded, parallel-group, placebo-controlled, active-comparator trial. J Sleep Res. 2012; 21(Suppl):1.

58. Ferini-Strambi L. Restless legs syndrome augmentation and pramipexole treatment. Sleep Med. 2002; 3(Suppl 3):23S-25S.

59. Silber MH, Girish M, Izurieta R. Pramipexole in the management of restless legs syndrome: an extended study. Sleep. 2003; 26:819-821. [PubMed: 14655914]

60. Stiasny-Kolster K, Oertel WH. Low-dose pramipexole in the management of restless legs syndrome. An open label trial. Neuropsychobiology. 2004; 50:65-70. [PubMed: 15179023]

61. Winkelman JW, Johnston L. Augmentation and tolerance with long-term pramipexole treatment of restless legs syndrome (RLS). Sleep Med. 2004; 5:9-14. [PubMed: 14725821]

62. Lipford MC, Silber MH. Long-term use of pramipexole in the management of restless legs syndrome. Sleep Med. 2012; 13:1280-1285. [PubMed: 23036265]

63. Garcia-Borreguero D, Kohnen R, Silber MH, et al. The long-term treatment of restless legs syndrome/Willis-Ekbom disease: evidence-based guidelines and clinical consensus best practice 
guidance: a report from the International Restless Legs Syndrome Study Group. Sleep Med. 2013; 14:675-684. [PubMed: 23859128]

64. Sun Y, van Valkenhoef G, Morel T. A mixed treatment comparison of gabapentin enacarbil, pramipexole, ropinirole and rotigotine in moderate-to-severe restless legs syndrome. Curr Med Res Opin. 2014; 30:2267-2278. [PubMed: 25050588]

65. Abetz L, Allen R, Follet A, et al. Evaluating the quality of life of patients with restless legs syndrome. Clin Ther. 2004; 26:925-935. [PubMed: 15262463]

66. Hays, RD.; Stewart, AL.; Stewart, AL.; Ware, JE. Measuring functioning and well-being: the medical outcomes study approach. Durham, NC: Duke University Press; 1992. Sleep measures; p. 235-259.

67. Hays RD, Martin SA, Sesti AM, Spritzer KL. Psychometric properties of the Medical Outcomes Study Sleep measure. Sleep Med. 2005; 6:41-44. [PubMed: 15680294]

68. Abetz L, Vallow SM, Kirsch J, Allen RP, Washburn T, Earley CJ. Validation of the Restless Legs Syndrome Quality of Life questionnaire. Value Health. 2005; 8:157-167. [PubMed: 15804324]

69. Allen R, Oertel W, Walters A, et al. Relation of the International Restless Legs Syndrome Study Group rating scale with the Clinical Global Impression severity scale, the restless legs syndrome 6item questionnaire, and the restless legs syndrome-quality of life questionnaire. Sleep Med. 2013; 14:1375-1380. [PubMed: 24246378]

70. Johns MW. A new method for measuring daytime sleepiness: the Epworth sleepiness scale. Sleep. 1991; 14:540-545. [PubMed: 1798888]

71. Jenkinson C, Coulter A, Wright L. Short form 36 (SF36) health survey questionnaire: normative data for adults of working age. BMJ. 1993; 306:1437-1440. [PubMed: 8518639] 


$$
\begin{aligned}
& 576 \text { papers identified by search strategy } \\
& \longrightarrow 138 \text { excluded duplicates } \\
& 438 \text { potentially relevant papers }
\end{aligned}
$$

\section{5 papers excluded}

2 trials that used a self-control method for pramipexole

2 trials that did not apply a washout period prior to the treatment

1 trial that used healthy volunteers as controls

1 trial that had treatment duration less than seven days

9 repeated records

12 papers included in final analysis

Figure 1.

Flow diagram of the screening process 


\begin{tabular}{|c|c|c|}
\hline \multicolumn{3}{|l|}{ Change on IRLS } \\
\hline BI 248.616 & 2008 & $-1.89(-3.83,0.05)$ \\
\hline Ferini-Strambi L, et al & 2008 & $-3.80(-5.74,-1.86)$ \\
\hline Hogl B, et al & 2009 & $-2.60(-4.82,-0.38)$ \\
\hline Ma JF, et al & 2012 & $-4.52(-6.74,-2.30)$ \\
\hline Montagna $\mathrm{P}$, et al & 2011 & $-6.10(-8.04,-4.16)$ \\
\hline Oertel WH, et al & 2007 & $-6.60(-8.72,-4.48)$ \\
\hline Partinen $\mathrm{M}$, et al & 2006 & $-8.93(-12.24,-5.61)$ \\
\hline Winkelman JW, et al & 2006 & $-4.22(-5.49,-2.95)$ \\
\hline Subtotal $($ I-squared $=70$ & $.4 \%, p=0.001)$ & $-4.64(-5.95,-3.33)$ \\
\hline \multicolumn{3}{|l|}{ Change in daytime tirednes } \\
\hline Ferini-Strambi L, et al & 2008 & $-3.80(-7.70,0.10)$ \\
\hline Hogl B, et al & 2009 & $0.10(-0.47,0.67)$ \\
\hline Montagna $\mathrm{P}$, et al & 2011 & $-1.10(-1.67,-0.53)$ \\
\hline Oertel WH, et al & 2007 & $-0.60(-0.88,-0.32)$ \\
\hline Subtotal $(1-$ squared $=73$ & $.3 \%, p=0.010)$ & $-0.61(-1.21,-0.01)$ \\
\hline \multicolumn{3}{|c|}{ Change in periodic limb movements in sleep per hour of sleep } \\
\hline Inoue $Y$, et al & 2010 & $-15.20(-27.85,-2.55)$ \\
\hline Montplaisir J, et al & $1999-$ & $-66.76(-90.98,-41.62)$ \\
\hline Partinen $\mathrm{M}$, et al & 2006 & $-29.67(-31.47,-27.87)$ \\
\hline \multicolumn{2}{|c|}{ Subtotal $(I-$ squared $=91.3 \%, p=0.000)$} & $-35.95(-56.42,-15.48)$ \\
\hline & -83.9 & 83.9 \\
\hline
\end{tabular}

Figure 2.

Forest plot of the change in the IRLS score, the change in daytime tiredness and the change in periodic limb movements per hour of sleep

The treatment outcomes for pramipexole were superior to those for placebo. IRLS: International RLS Study Group Rating Scale 
Events, Events, \%

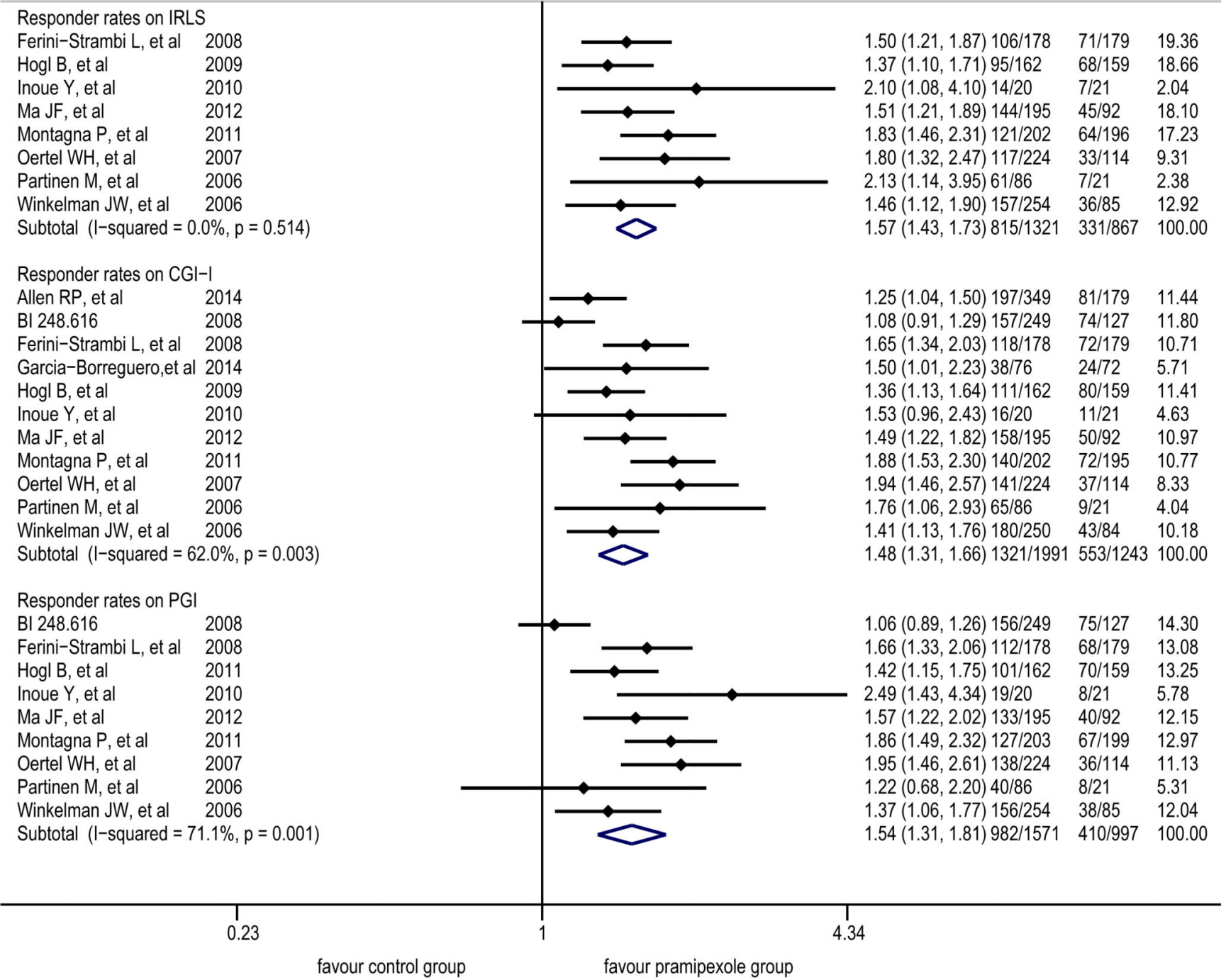

Figure 3.

Forest plot of the responder rates for the IRLS score, the responder rates for the CGI-I, and the responder rates for the PGI

The treatment outcomes for pramipexole were superior to those for placebo. IRLS: International RLS Study Group Rating Scale; CGI-I: Clinical Global Impression of Improvement scale; PGI: Patient Global Impression scale 


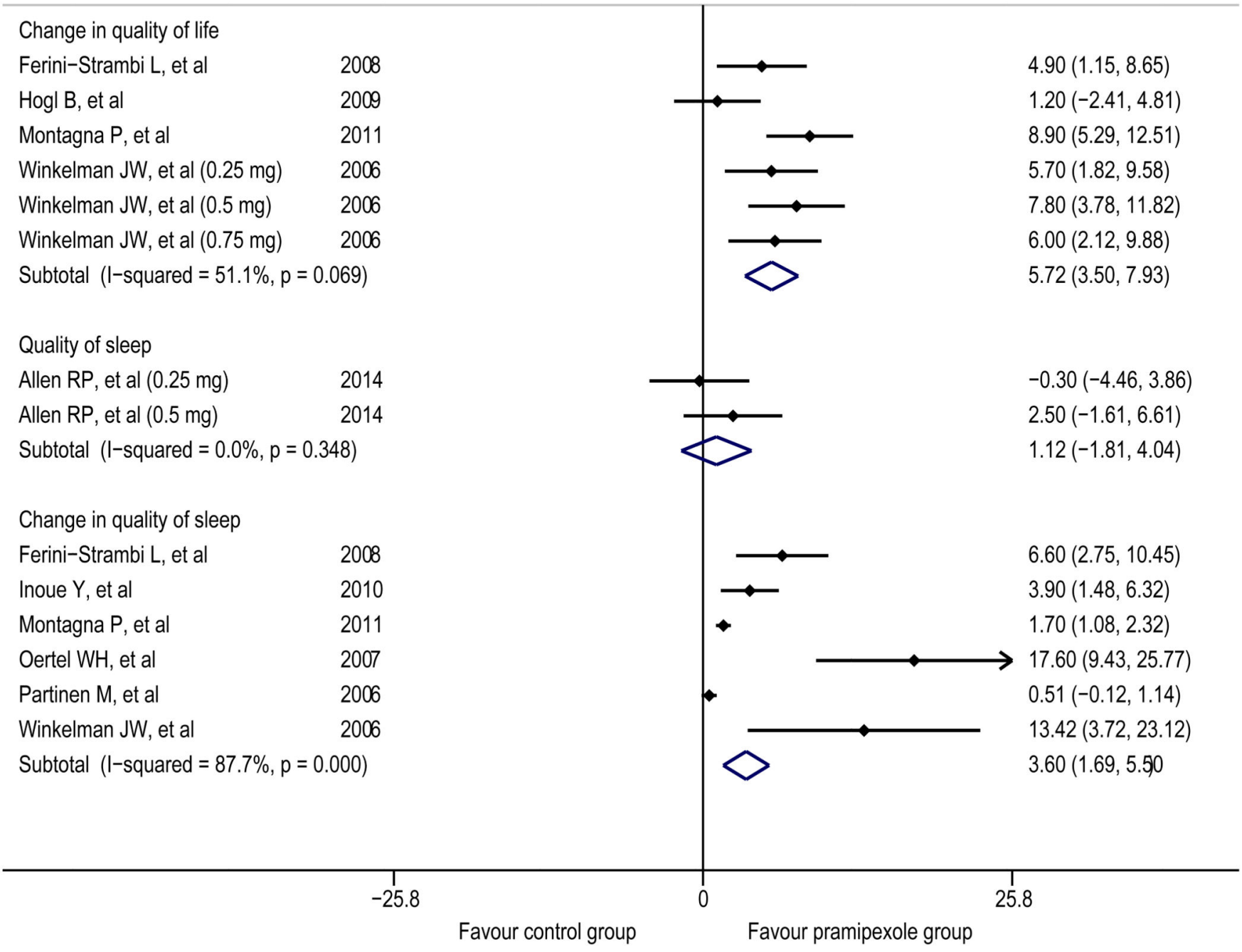

Figure 4.

Forest plot of the change in quality of life, the quality of sleep and the change in quality of sleep The treatment outcomes for pramipexole were superior to those for placebo for the change in quality of life and the change in quality of sleep. 
Table 1

\section{Trial Characteristics}

\begin{tabular}{|c|c|c|c|}
\hline Trials & $\begin{array}{l}\text { Participants (Pramipexole } \\
\text { group vs. } \\
\text { placebo group) }\end{array}$ & Intervention (Pramipexole group) & Outcomes \\
\hline Allen et al. ${ }^{30}$ & $\begin{array}{l}\mathrm{n}=537 \text { (excluding the } \\
\text { patients treated } \\
\text { with pregabalin), and the } \\
\text { average } \\
\text { age was } 55.34( \pm 13.19) \text { vs. } \\
53.5 \\
( \pm 13.3) \text {; males accounted for } \\
42.18 \% \\
\text { vs. } 38.0 \% \text {; the duration of } \\
\text { symptoms } \\
\text { was at least six months, and } \\
\text { the } \\
\text { baseline IRLS score was } \\
22.25 \\
( \pm 5.30) \text { vs. } 22.4( \pm 5.6)\end{array}$ & $\begin{array}{l}\text { Pramipexole } 0.25 \text { or } 0.5 \mathrm{mg} / \text { day (once daily); } \\
\text { the dose build-up phase was } 2 \text { weeks, and the } \\
\text { maintenance period was } 10 \text { weeks }\end{array}$ & $\begin{array}{l}12 \text { weeks; IRLS score, } \\
\text { responder rates on } \\
\text { CGI-I, quality of life with a } \\
\text { questionnaire }^{65} \\
\text { quality of sleep with a } \\
\text { questionnaire }^{66}\end{array}$ \\
\hline $\mathrm{BI} 248.616^{20}$ & $\begin{array}{l}\mathrm{N}=373 \text {, and the average age } \\
\text { was } \\
48.69( \pm 1.49) \text { vs. } 49.6( \pm 1) \\
\text { years; } \\
\text { males accounted for } 29.74 \% \\
\text { vs. } \\
39.39 \% \text {; no indication was } \\
\text { provided } \\
\text { for the duration of } \\
\text { symptoms; the } \\
\text { baseline IRLS score was } 25 \\
\text { vs. } 24.9\end{array}$ & $\begin{array}{l}\text { Pramipexole at a fixed dose of } 0.25 \mathrm{mg} / \text { day (once } \\
\text { daily) } \\
\text { with a treatment duration of } 6 \\
\text { weeks for intervention group A; for } \\
\text { intervention group B, } 0.125 \mathrm{mg} / \text { day (once } \\
\text { daily) for } 1 \text { week and } 0.25 \mathrm{mg} / \text { day (once daily) } \\
\text { for } 5 \text { weeks }\end{array}$ & $\begin{array}{l}6 \text { weeks; change in the IRLS; } \\
\text { responder rates } \\
\text { for the IRLS score; responder } \\
\text { rates for the } \\
\text { CGI-I; responder rates for the } \\
\text { PGI }\end{array}$ \\
\hline Ferini-Strambi et al. ${ }^{25}$ & $\begin{array}{l}\mathrm{n}=357, \text { and the average age } \\
\text { was } 56.3 \\
( \pm 12.4) \text { vs. } 56.9( \pm 13.0) \\
\text { years; males } \\
\text { accounted for } 27.5 \% \text { vs. } \\
36.4 \% \text {; the } \\
\text { duration of symptoms was } \\
5.36 \\
( \pm 9.78) \text { vs. } 5.66( \pm 9.89) \\
\text { year; the } \\
\text { baseline IRLS score was } \\
24.2( \pm 5.2) \\
\text { vs. } 24.6( \pm 5.7)\end{array}$ & $\begin{array}{l}\text { Pramipexole } 0.25,0.5 \text {, or } 0.75 \mathrm{mg} / \mathrm{day} \text { (once } \\
\text { daily); the dose build-up duration was } 4 \text { weeks, } \\
\text { and the maintenance period was } 8 \text { weeks }\end{array}$ & $\begin{array}{l}12 \text { weeks; IRLS score; } \\
\text { responder rates for the } \\
\text { IRLS score; responder rates } \\
\text { for the CGI-I; } \\
\text { responder rates for the PGI; } \\
\text { Medical } \\
\text { Outcomes Study sleep } \\
\text { scale; }^{67} \text { the Johns } \\
\text { Hopkins RLS Quality of Life } \\
\text { (RLS-QOL) } \\
\text { questionnaire score }\end{array}$ \\
\hline $\begin{array}{l}\text { Garcia-Borreguero } \\
\text { et al. }\end{array}$ & $\begin{array}{l}\mathrm{n}=148 \text { (excluding the } \\
\text { patients treated } \\
\text { with pregabalin), and the } \\
\text { average } \\
\text { age ranged from } 50.3 \text { to } 57.4 \\
\text { years; } \\
\text { males accounted for } 36 \% \text {, } \\
\text { and the } \\
\text { duration of symptoms ranged } \\
\text { from } 2 \\
\text { to } 11.9 \text { years; no indication } \\
\text { of the } \\
\text { baseline IRLS score was } \\
\text { provided }\end{array}$ & $\begin{array}{l}\text { Crossover trial; all participants were } \\
\text { randomized across } 6 \text { treatment sequences, each } \\
\text { comprising } 3 \text { double-blind treatment periods } \\
\text { with pregabalin } 300 \mathrm{mg} / \text { day (once daily), } \\
\text { pramipexole } 0.5 \mathrm{mg} / \text { day (once daily; dose } \\
\text { began at } 0.125 \mathrm{mg} / \text { day), and placebo. Each } \\
\text { treatment period included } 10 \text { days' dose } \\
\text { escalation and } 19 \text { days' fixed-dose treatment. } \\
\text { Following each treatment period, the drug } \\
\text { dosage was tapered over } 6 \text { days }\end{array}$ & $\begin{array}{l}12 \text { weeks; periodic limb } \\
\text { movements during } \\
\text { time in bed index (PLMI); } \\
\text { responder rates for } \\
\text { the CGI-I; quality of sleep } \\
\text { score (Epworth } \\
\text { Sleepiness scale (ESS)); } \\
\text { quality of life (the } \\
\text { Johns Hopkins RLS Quality } \\
\text { of Life } \\
\text { (RLS-QOL) questionnaire } \\
\text { score) }\end{array}$ \\
\hline Högl et al. ${ }^{27}$ & $\begin{array}{l}\mathrm{n}=321 \text {, and the average age } \\
\text { was } 57.9 \\
( \pm 12.7) \text { vs. } 55.8( \pm 14.1) \\
\text { years; males } \\
\text { accounted for } 38.6 \% \text { vs. } \\
42.3 \% \text {; the } \\
\text { duration of symptoms was } \\
6.0( \pm 9.6) \\
\text { vs. } 5.4( \pm 8.5) \text { years, and the } \\
\text { baseline }\end{array}$ & $\begin{array}{l}\text { Pramipexole; the initial dose was } 0.12 \mathrm{mg} / \text { day } \\
\text { (once daily), which was gradually adjusted to } \\
\text { an acceptable dose of } 0.125,0.25,0.5 \text {, or } 0.75 \\
\text { mg/day (once daily); the dose build-up } \\
\text { duration was } 4 \text { weeks, and the maintenance } \\
\text { period was } 22 \text { weeks }\end{array}$ & $\begin{array}{l}26 \text { weeks; change in the } \\
\text { IRLS; responder rates } \\
\text { for the IRLS score; responder } \\
\text { rates for the } \\
\text { CGI-I; responder rates for the } \\
\text { PGI; RLS-6 } \\
\text { rating scales; } 69 \text { the Johns } \\
\text { Hopkins RLS }\end{array}$ \\
\hline
\end{tabular}

Clin Ther. Author manuscript; available in PMC 2017 January 01. 


\begin{tabular}{|c|c|c|c|}
\hline Trials & $\begin{array}{l}\text { Participants (Pramipexole } \\
\text { group vs. } \\
\text { placebo group) }\end{array}$ & Intervention (Pramipexole group) & Outcomes \\
\hline & $\begin{array}{l}\text { score was } 23.9( \pm 5.3) \text { vs. } \\
23.5( \pm 5.4)\end{array}$ & & $\begin{array}{l}\text { Quality of Life (RLS-QOL) } \\
\text { questionnaire } \\
\text { score }^{68}\end{array}$ \\
\hline Inoue et al. ${ }^{26}$ & $\begin{array}{l}\mathrm{n}=37, \text { and the average age } \\
\text { was } 48.7 \\
( \pm 16.1) \text { vs. } 62.3( \pm 11.9) \\
\text { years; males } \\
\text { accounted for } 45.0 \% \text { vs. } \\
52.4 \% \text {; the } \\
\text { duration of symptoms was } \\
0.22 \\
( \pm 0.55) \text { vs. } 0.64( \pm 1.28) \\
\text { years; the } \\
\text { baseline IRLS score was } \\
23.4( \pm 6.4) \\
\text { vs. } 25.1( \pm 5.8)\end{array}$ & $\begin{array}{l}\text { Pramipexole; the initial dose was } 0.12 \mathrm{mg} / \text { day } \\
\text { (once daily), which was gradually increased to } \\
0.25,0.5 \text {, or } 0.75 \mathrm{mg} \text { /day (once daily); the } \\
\text { dose build-up duration was } 1 \text { week, and the } \\
\text { maintenance period was } 5 \text { weeks }\end{array}$ & $\begin{array}{l}6 \text { weeks; IRLS score; } \\
\text { responder rates for the } \\
\text { CGI-I; responder rates for the } \\
\text { PGI; Epworth } \\
\text { Sleepiness Scale (ESS); }{ }^{.70} \text { the } \\
\text { Pittsburgh Sleep } \\
\text { Quality Index }\end{array}$ \\
\hline Ma et al. ${ }^{29}$ & $\begin{array}{l}\mathrm{n}=305 \text {, and the average age } \\
\text { was } \\
56.46( \pm 11.88) \text { vs. } 56.86 \\
( \pm 11.89) \\
\text { years; males accounted for } \\
39.6 \% \text { vs. } \\
27.7 \% \text {; the duration of } \\
\text { symptoms } \\
\text { was at least } 3 \text { months; the } \\
\text { baseline } \\
\text { IRLS score was at least } 15\end{array}$ & $\begin{array}{l}\text { Pramipexole; the initial dose was } 0.125 \\
\text { mg/day (once daily), which was increased to } \\
\text { an "suitable dose" based on effectiveness and } \\
\text { tolerance using a titration method; the dose } \\
\text { build-up duration was } 4 \text { weeks, and the } \\
\text { maintenance period was } 2 \text { weeks }\end{array}$ & $\begin{array}{l}6 \text { weeks; IRLS score; } \\
\text { responder rates for the } \\
\text { IRLS score; responder rates } \\
\text { for the CGI-I; } \\
\text { responder rates for the PGI; } \\
\text { visual analog } \\
\text { scales; Epworth sleepiness } \\
\text { scale (ESS); }{ }^{70} \\
\text { RLS-6 rating scales }{ }^{69}\end{array}$ \\
\hline Montagna et al. ${ }^{28}$ & $\begin{array}{l}\mathrm{N}=403 \text {, and the average age } \\
\text { was } \\
55.0( \pm 13.8) \text { vs. } 56.1( \pm 12.1) \\
\text { years; } \\
\text { males accounted for } 33.0 \% \\
\text { vs. } 27 \% \text {; } \\
\text { the duration of symptoms } \\
\text { was } 3.5 \\
( \pm 7.2) \text { vs. } 3.3( \pm 6.5) \text { year; } \\
\text { the } \\
\text { baseline IRLS score was } \\
25.9( \pm 5.2) \\
\text { vs. } 25.9( \pm 5.5)\end{array}$ & $\begin{array}{l}\text { Pramipexole; the initial dose was } 0.125 \\
\mathrm{mg} / \text { day (once daily), which was increased to } \\
0.125,0.25,0.5 \text {, or } 0.75 \mathrm{mg} / \text { day (once daily) } \\
\text { based on effectiveness and tolerance using a } \\
\text { titration method; the dose build-up duration } \\
\text { was } 4 \text { weeks, and the maintenance period was } \\
8 \text { weeks }\end{array}$ & $\begin{array}{l}12 \text { weeks; IRLS score; } \\
\text { responder rates for the } \\
\text { IRLS score; responder rates } \\
\text { for the CGI-I; } \\
\text { responder rates for the PGI; } \\
\text { RLS-6 rating } \\
\text { scales; } 69 \text { the Johns Hopkins } \\
\text { RLS Quality of } \\
\text { Life (RLS-QOL) } \\
\text { questionnaire score; } 68 \text { the } \\
\text { Hospital Anxiety and } \\
\text { Depression } \\
\text { Scale-Anxiety subscale } \\
\text { (HADS-A) score }\end{array}$ \\
\hline Montplaisir et al. ${ }^{21}$ & $\begin{array}{l}\mathrm{n}=20 \text {, and the average age } \\
\text { was } 49.3 \\
( \pm 11.5) \text { years; males } \\
\text { accounted for } \\
55.56 \% \text {; the duration of } \\
\text { symptoms } \\
\text { was at least one year; the } \\
\text { baseline } \\
\text { IRLS score was not } \\
\text { mentioned }\end{array}$ & $\begin{array}{l}\text { Crossover trial; pramipexole group received } \\
\text { flexible up-titration of pramipexole (once } \\
\text { daily) from } 0.375 \mathrm{mg} \text { to } 0.75 \mathrm{mg} \text { to } 1.5 \mathrm{mg} \text { in } 2 \\
\text { weeks and maintenance for } 2 \text { weeks; placebo } \\
\text { group received placebo for } 4 \text { weeks; } 2 \text { week } \\
\text { washout between phases }\end{array}$ & $\begin{array}{l}8 \text { weeks; periodic limb } \\
\text { movements per hour of } \\
\text { sleep measured under PSG } \\
\text { monitoring }\end{array}$ \\
\hline Oertel et al. ${ }^{24}$ & $\begin{array}{l}\mathrm{n}=338, \text { and the average age } \\
\text { was } 55.4 \\
( \pm 11.6) \text { vs. } 55.8( \pm 10.9) \\
\text { years; males } \\
\text { accounted for } 35.7 \% \text { vs. } \\
31.6 \% \text {; the } \\
\text { duration of symptoms was } \\
4.95 \\
( \pm 9.21) \text { vs. } 9.06( \pm 5.63) \\
\text { years, the } \\
\text { baseline IRLS score was } \\
24.7( \pm 5.2) \\
\text { vs. } 24.9( \pm 5.4)\end{array}$ & $\begin{array}{l}\text { Pramipexole; the initial dose was } 0.125 \\
\text { mg/day (once daily), which was increased to } \\
0.25,0.5 \text {, or } 0.75 \mathrm{mg} / \text { day (once daily) based on } \\
\text { effectiveness and tolerance using a titration } \\
\text { method; the dose build-up duration and } \\
\text { maintenance period were not mentioned }\end{array}$ & $\begin{array}{l}6 \text { weeks; IRLS score; } \\
\text { responder rates for the } \\
\text { CGI-I; responder rates for the } \\
\text { IRLS score; } \\
\text { responder rates for the PGI; } \\
\text { visual analogue } \\
\text { scales }\end{array}$ \\
\hline Partinen et al. ${ }^{22}$ & $\begin{array}{l}\mathrm{n}=108 \text {, and the average age } \\
\text { was } 56.2\end{array}$ & $\begin{array}{l}\text { Pramipexole; the initial dose was } 0.125 \\
\text { mg/day (once daily), which was increased to a } \\
\text { pre-established dose of } 0.125,0.25,0.5 \text {, or }\end{array}$ & $\begin{array}{l}3 \text { weeks; IRLS score; } \\
\text { responder rates for the }\end{array}$ \\
\hline
\end{tabular}

Clin Ther: Author manuscript; available in PMC 2017 January 01. 


\begin{tabular}{|c|c|c|c|}
\hline Trials & $\begin{array}{l}\text { Participants (Pramipexole } \\
\text { group vs. } \\
\text { placebo group) }\end{array}$ & Intervention (Pramipexole group) & Outcomes \\
\hline & $\begin{array}{l}( \pm 10.9) \text { years; males } \\
\text { accounted for } \\
38.71 \% \text { vs. } 19.05 \%, \text { the } \\
\text { duration of } \\
\text { symptoms was } 4.8( \pm 10.4) \\
\text { years, and } \\
\text { the baseline IRLS score was } \\
22.7 \\
( \pm 4.1) \text { in total }\end{array}$ & $\begin{array}{l}0.75 \mathrm{mg} / \text { day (once daily) using a titration } \\
\text { method; the dose build-up duration was } 4 \text { days, } \\
\text { and the maintenance period was } 17 \text { days }\end{array}$ & $\begin{array}{l}\text { PGI; responder rates for the } \\
\text { CGI-I; responder } \\
\text { rates for the IRLS score; the } \\
\text { Pittsburgh Sleep } \\
\text { Quality Index; sleepiness and } \\
\text { sleep quality } \\
(\text { Epworth Sleepiness Scale } \\
(\text { ESS) } \\
\text { life; quality of } \\
\text { Survey } \\
\left.\text { questionnaire }{ }^{71}\right) \text {; periodic } 36 \text { Health } \\
\text { limb movements } \\
\text { during time in bed index } \\
\text { (PLMI) }\end{array}$ \\
\hline Winkelman et al. ${ }^{23}$ & $\begin{array}{l}\mathrm{n}=339, \text { and the average age } \\
\text { was } 51.4 \\
( \pm 13) \text { years; males accounted } \\
\text { for } \\
38.19 \% \text { vs. } 36.47 \% \text {, the } \\
\text { duration of } \\
\text { symptoms } 5.1( \pm 15) \text { years, } \\
\text { the } \\
\text { baseline IRLS score was } \\
23.4( \pm 5.1) \\
\text { vs. } 23.5( \pm 5.2)\end{array}$ & $\begin{array}{l}\text { Pramipexole; the initial dose was } 0.125 \\
\mathrm{mg} / \mathrm{day} \text { (once daily), which was increased to a } \\
\text { pre-established dose of } 0.25,0.5 \text { or } 0.75 \\
\mathrm{mg} / \mathrm{day} \text { (once daily) based on the effectiveness } \\
\text { and tolerance; the dose build-up duration was } 3 \\
\text { weeks, and the maintenance period was } 9 \\
\text { weeks }\end{array}$ & $\begin{array}{l}12 \text { weeks; IRLS score; } \\
\text { responder rates for the } \\
\text { CGI-I; responder rates for the } \\
\text { PGI; responder } \\
\text { rates for the IRLS score; } \\
\text { daytime somnolence } \\
\text { (Epworth sleepiness scale } \\
\text { (ESS));70 quality of } \\
\text { life (the Johns Hopkins RLS } \\
\text { Quality of Life } \\
\text { (RLS-QOL) questionnaire } \\
\text { score) }\end{array}$ \\
\hline
\end{tabular}

RLS: Restless Legs Syndrome; IRLS: International RLS Study Group Rating Scale; CGI-I: Clinical Global Impression of Improvement scale; PGI: Patient Global Impression scale; MOS: Medical Outcomes Study sleep disturbance score; RLS-QOL: Johns Hopkins RLS Quality of Life Scale; RLS-6: RLS 6-item questionnaire; ESS: Epworth sleepiness scale

Results are shown as mean \pm standard deviation. 

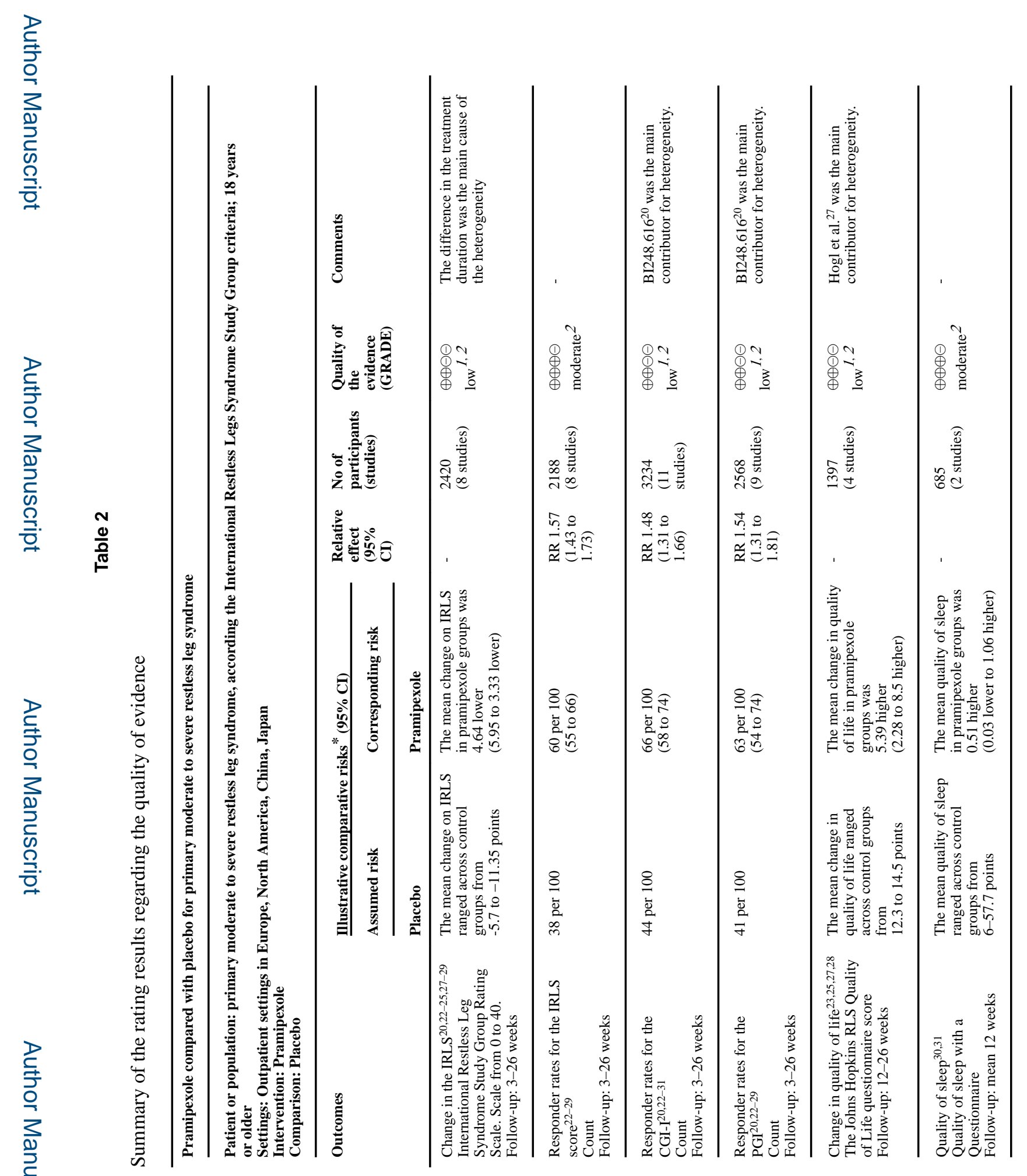

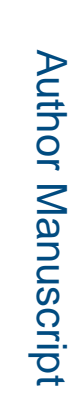

Clin Ther: Author manuscript; available in PMC 2017 January 01. 


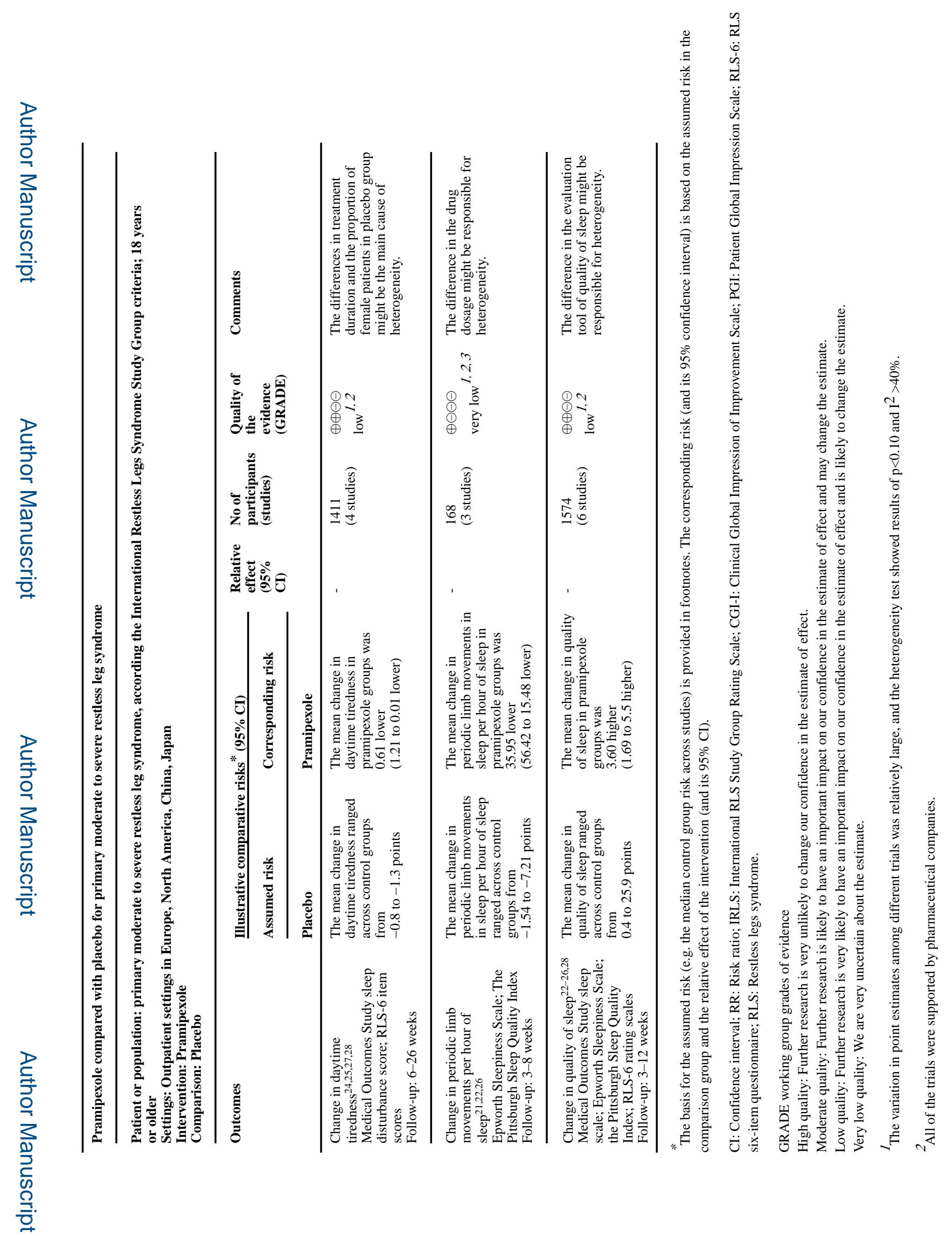

Clin Ther. Author manuscript; available in PMC 2017 January 01. 


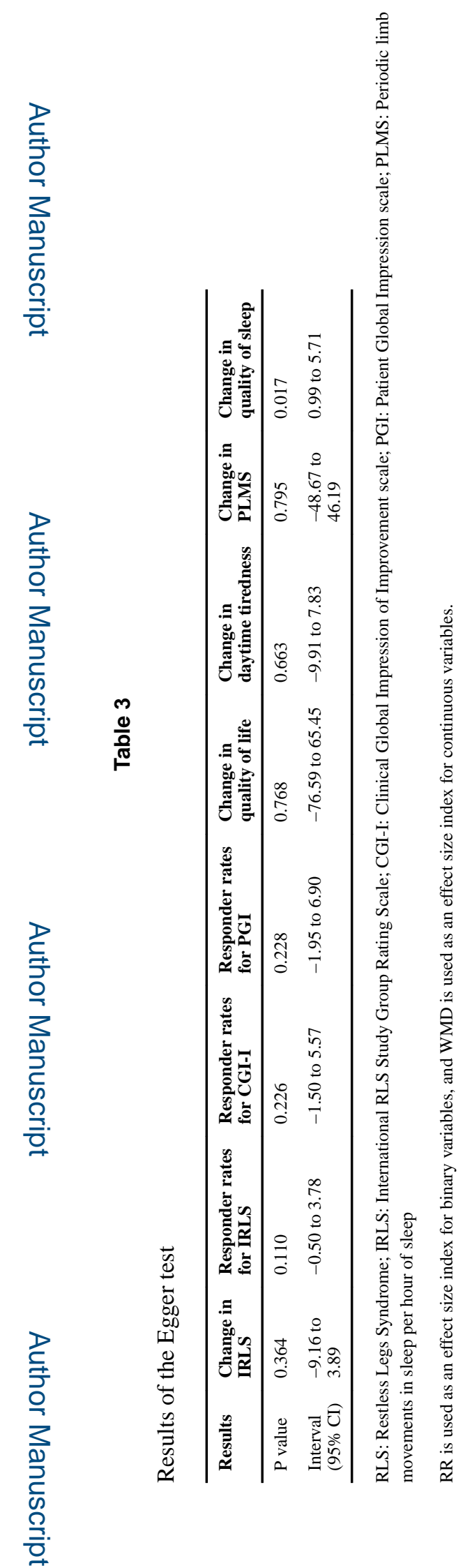

Clin Ther. Author manuscript; available in PMC 2017 January 01. 